\title{
IVF laboratory COVID-19 pandemic response plan: a roadmap
}

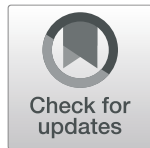

Fadi Choucair ${ }^{1,2^{*}}$ D, Nagham Younis , $^{1,3}$ and Alia Hourani ${ }^{1,4}$

\begin{abstract}
Background: The potential of COVID-19 severe pandemic necessitates the development of an organized and wellreasoned plan for the management of embryology/andrology laboratories while safeguarding the wellbeing of patients and IVF staff.

Main body: A COVID-19 pandemic response plan was proposed for embryology and andrology laboratories for pre-pandemic preparedness and pandemic management in anticipation of a possible second coronavirus wave. Preparation involves many plans and logistics before a pandemic risk rises. Many operational changes can be considered during the pandemic. This plan includes logistical arrangements, reducing labor needs, conserving supplies, and protective measures for embryologists and gametes/embryos.
\end{abstract}

Conclusion: The unpredictable emergence of the COVID-19 pandemic dictates the need for a preparedness plan for embryology/andrology laboratories, which includes an action-oriented plan to secure the safety of all stakeholders.

Keywords: COVID-19, Pandemic, Response plan, In vitro fertilization laboratory, Clinical embryology, Andrology, Emergency

\section{Background}

In view of the recent worldwide COVID-19 disease and predictions suggesting the inevitability of future pandemics, the need for a disaster plan for IVF laboratories has become a compulsory requirement. COVID-19 is caused by a virus from the coronaviridae family, named severe acute respiratory syndrome coronavirus 2 (SARS$\mathrm{CoV}-2$ ) [1]. Coronaviruses can be transmitted through the air in respiratory droplets $(>5-\mu \mathrm{m}$ diameter $)$ and aerosols $(\leq 5-\mu \mathrm{m}$ diameter). Transmission is also believed to occur through direct (contaminated hands) or indirect (contaminated surfaces and fomites) physical contacts, leading to cross-infections and outbreaks [2]. According to the most recent evidence from the World Health Organization (WHO) and the US Centers for

\footnotetext{
*Correspondence: fc13@aub.edu.lb

${ }^{1}$ Middle East Fertility Society Embryology Specialty Interest Group, Beirut, Lebanon

${ }^{2}$ American University of Beirut Medical Center, Beirut, Lebanon

Full list of author information is available at the end of the article
}

Disease Control and Prevention (CDC), the predominant transmission route for coronaviruses is through droplets as the virus is conveyed by exhaled air (through normal breathing, coughing or sneezing) rather than aerosols [3, 4]. These heavy droplets can deposit on surfaces amplifying the propagation of the virus. Surprisingly, recent data showed that the prevalence of asymptomatic individuals with COVID-19 may be as high as 50-75\% which challenges the triage of infected individuals [5].

It is estimated that more than $25 \%$ of transmissions occur in the workplace [6]. The occurrence of asymptomatic coronavirus-positive patients and healthcare workers in IVF units may contribute to an environment rich in respiratory viruses, leading to potential outbreaks in the working place and spillover into the community. In this regard, it was reported that coronaviruses have been implicated in nosocomial community outbreaks originating from hospitals $[7,8]$. 


\section{Potential biological transmission}

Several molecular characteristics of SARS-CoV-2 may justify concerns about the potential susceptibility of gametes (semen, testicular tissue) and embryos to viral infection [9, 10]. Although not universally supported [11-13], recent reports confirmed the presence of the virus in the semen of infected patients [14]. These findings justify calls for more vigilance in the work environment and for the need to put in place stringent measures to protect embryologists from potentially infected gametes.

The possibility of coronavirus survival in liquid nitrogen is currently not known, but it is suggested that viruses are likely to survive the freeze/thaw process [15]. During cryopreservation of gametes/embryos in liquid nitrogen, straws or vials may leak or shatter causing liquid nitrogen spill and potential cross-contamination of samples. Using an experimental model, Bielanski and colleagues confirmed the occurrence of viral cross-contamination of bovine embryos stored in liquid nitrogen by bovine airborne viruses [16]. In addition, the sterility of factory-derived liquid nitrogen is often not guaranteed, and the risk of contamination by human pathogens may theoretically exist. In theory, some airborne contaminants may contaminate liquid nitrogen during the process of gas compression [16]. When cryotanks are opened, the nitrogen vapor mixes with the atmospheric air creating ice sediments which falls into the vessel and accumulates at its bottom. During aggregation, these ice crystals may entrap various airborne microbes (bacteria, fungi...) leading to possible contamination of the cryotanks [17]. It follows that the risk of contamination and cross-contamination of cryopreserved human material in liquid nitrogen by nosocomial coronaviruses is of legitimate concern.

\section{Occupational person-to-person transmission}

Apart from direct viral transmission, the presence of patients and healthcare workers in a tight and closed working space in the presence of a variety of pathologies causes the fomites and the air to be loaded with potential viral contaminants. Occupational transmission in clinical laboratories is exceptional events rarely reported. At present no data are available for coronavirus outbreaks in IVF laboratories. Nevertheless, it is evident that in clinical laboratory settings, infection prevention and control measures are often designed to act on most pathogen's modes of transmission.

\section{The professional societies response}

Professional societies, such as the American Society for Reproductive Medicine (ASRM) and the European Society for Human Reproduction and Embryology (ESHRE), have strongly urged to stop fertility treatments during the COVID-19 pandemic for the protection of human life (i.e., conceptus). The majority of these societies provided guidance for IVF laboratories for the gradual resumption of activities throughout the pandemic [18-21]. As COVID-19 keeps on spreading comprehensively, escalating case importation from overseas or residual infected seeds coupled with the resumption of economic activities, a second wave of COVID-19 seems plausible.

To meet these challenges, the authors, on behalf of the Middle East Fertility Society Embryology group, developed a response plan to outline the essential services and delineate the proper means to ensure the sustainability of IVF laboratory services in anticipation of a second COVID-19 pandemic wave. To that end, the authors aimed to provide a practical roadmap for a preparedness and management plan for the protection of human life (gametes/embryos and staff). It should be noted that some points raised might represent standard of practice in IVF or basic requirements for IVF laboratories accreditation. It is important to emphasize nonetheless that while these recommendations constitute appropriate guidelines for IVF laboratory management during a COVID-19 pandemic, they are not designed to dictate a rigid all-exclusive plan.

\section{Main text}

Heightened planning and logistic preparation: initial onset of a pandemic

It is widely accepted that proper pre-pandemic planning should occur at an early level, as outlined in Table 1 and discussed later. Several initial logistic preparations should be in order before the occurrence of the crisis. Although most of these preparatory steps comply with the basic emergency plan of the IVF laboratory, some important elements may require further highlighting. Basically, and as part of routine infection control practices, the IVF staff should receive adequate education and proper training on conventional infection control practices and standard operating procedures (SOP) [22].

Hand hygiene compliance observation audits should be periodically performed with special focus on avoiding touching noses, mouths, and eyes [23].

In an effort to reduce the burden of the pandemic on the healthcare system, embryologists are encouraged to obtain additional vaccination namely for preventing respiratory illness caused by influenza and pertussis [24]. Personnel should also participate in a fit testing for N95 masks (FFP2 the European equivalent) which provides protection against aerosol-generated particles [28]. This test ensures that masks are properly sealed to the face.

As part of the main laboratory emergency plan, the IVF personnel should know whom to contact during an emergency crisis $[25,26]$. Along this perspective, the laboratory supervisor should prepare staff emergency and 
Table 1 Early-level response plan: pre-pandemic planning recommendations for embryology and andrology laboratories

\begin{tabular}{ll}
\hline Recommendation & Basis of evidence \\
\hline Educate staff on disease transmission and mitigation methods & Recommendation based on consensus guidelines (CDC) [22] \\
Perform hand hygiene compliance observation audits & Recommendation based on a systematic review [23] \\
Consider additional vaccination for preventing respiratory illness & Recommendation based on the WHO position paper [24] \\
Perform fit testing for N95 masks & Recommendation based on expert opinion \\
Stock essential PPE supply & Recommendation based on expert opinion \\
Prepare staff emergency contact lists & Recommendation based on a committee opinion paper (SART, ASRM) and \\
Update and maintain records on a remote server & guidelines (ESHRE for good practice) [25, 26] \\
Dedicate a spare storage cryotank and sufficient liquid nitrogen supply & Recommendation based a committee opinion paper (SART, ASRM) [25] \\
Clean regularly the cryotanks & Recommendation based on accreditation standards (College of American \\
Store spare gas cylinders & Recommendation based on risk assessment research [16] \\
\hline
\end{tabular}

suppliers contact lists and make them accessible to all staff. More importantly, duplicate records must be maintained on a secure web server and updated regularly [25].

The supervisor must also make sure to stock essential PPE supply. Facilities must consider storing cleaned spare gas cylinders in a ventilated storage room to avoid supply chain failure during pandemic times [29].

It should be noted that an on-site spare storage cryotank and reserve of liquid nitrogen (LN2) supply are critical points which constitute requirements for laboratory accreditation (College of American Pathologists (CAP) accreditation 2019 checklist; RLM.03944) [27]. The laboratory should have a written procedure to monitor and maintain adequate liquid nitrogen levels and temperatures (CAP accreditation 2019; RLM.03940). The monitoring can be through visual measurement, weight scaling, or use of an alarm system [30]. Cryopreservation consents should state the possibility of system failures during storage in case of disasters [25]. The cryotanks require periodic decontamination using approved laboratory detergents with adequate rinsing with distilled water [16]. The decontamination of cryotanks is recommended owing to the potential accumulation of sediments and contamination of liquid nitrogen [16]. However, this practice is optional and is not recommended by the regulating reproductive societies (ESHRE, ASRM, CAP).

\section{Operational changes during the pandemic stages}

Due to the nature of coronavirus transmission, the WHO advocated and enforced "social distancing" measures to maintain the 2-m "safe" distance between people in addition to the routine use of PPE [31, 32]. As previously mentioned, the high proportion of asymptomatic individuals may imply that an infected asymptomatic embryologist may infect his/her colleagues if adequate protective measures and gears are not properly used. In addition, staff should be educated to recognize early signs of viral illness, namely sore throat, fever, and cough.

As numerous plans for work have been proposed by professional societies and regulations bodies across the globe during the pandemic period, it seems reasonable for healthcare workers to adopt these measures through normal times in anticipation of new pandemic waves.

In extreme scenarios, the complete closure of IVF clinics and the total cessation of all procedures are recommended in the event of a new pandemic. However, in the "new normal" operational practices, many interventions may be changed to adapt to the pandemic risk (Table 2).

\section{Operational changes reducing labor needs and conserving supplies}

Several operational changes should be implemented in the IVF laboratory in order to maintain the continuity of care by ensuring the safety of the personnel and avoiding the shortage in supplies.

To meet these goals, laboratory managers are expected to identify the right people to fulfill the essential roles. In spite of a forced shut-down policy during a pandemic, some procedures such as oocyte vitrification for oncology patients are deemed to be of urgent nature. In such cases, the supervisor should also explore the option of hiring free-lancers to fulfill essential tasks. In other words, the number of embryologists reporting to work should be reduced to a minimum without compromising safety and quality. Embryologists would be expected to perform rotating shifts depending on the size of the unit and staff. The rotating schedule is created to minimize exposure time to infection while accommodating the continuity of care within the laboratory [18]. 
Table 2 Pandemic response plan: recommendations for embryology and andrology laboratories during the coronavirus pandemic

\begin{tabular}{|c|c|}
\hline Recommendations & Basis of evidence \\
\hline \multicolumn{2}{|l|}{ Operational changes reducing labor needs and conserving supplies } \\
\hline Identify essential the right people to fulfill the essential roles & Recommendation based on expert opinion \\
\hline Create rotation shifts & $\begin{array}{l}\text { Recommendation based on committee opinion } \\
\text { guidelines (ESHRE COVID-19 taskforce) [18] }\end{array}$ \\
\hline $\begin{array}{l}\text { Stock PPE and cryopreservation medium and culture media batches } \\
\text { favoring products with longer expiration dates }\end{array}$ & Recommendation based on expert opinion \\
\hline Reduce the number of operated incubators & Recommendation based on expert opinion \\
\hline \multicolumn{2}{|l|}{ Operational changes protecting embryologists and gametes/embryos } \\
\hline $\begin{array}{l}\text { Perform triage of staff and patients, and test according to the national } \\
\text { recommendations and/or availability of laboratory testing }\end{array}$ & $\begin{array}{l}\text { Recommendation based on committee opinion } \\
\text { guidelines (ESHRE, ASRM COVID-19 taskforce) }[18,19]\end{array}$ \\
\hline $\begin{array}{l}\text { Use proper PPE (surgical masks, gloves) or N95 masks when performing } \\
\text { an aerosol-generating procedure }\end{array}$ & Recommendation based on experimental research [28] \\
\hline Wear a surgical mask and practice social distancing at all time & $\begin{array}{l}\text { Recommendation based on public health } \\
\text { epidemiologic data [32] }\end{array}$ \\
\hline $\begin{array}{l}\text { Postpone visits for cryopreservation storage renewal payment and } \\
\text { allow online billing using an electronic medical record system }\end{array}$ & Recommendation based on expert opinion \\
\hline Perform cryopreservation consenting online & Recommendation based on expert opinion \\
\hline $\begin{array}{l}\text { Cleaning practices must be performed by laboratory staff (surfaces, } \\
\text { keyboards, doorknobs, supplies boxes...) }\end{array}$ & Recommendation based on usual practice \\
\hline $\begin{array}{l}\text { Continuing positive-pressure air purification, reducing air recirculation, } \\
\text { and favoring } 100 \% \text { fresh air }\end{array}$ & Recommendation based on expert opinion \\
\hline $\begin{array}{l}\text { Spray and wipe with approved disinfectant followed by UV irradiation } \\
\text { for } 30 \text { min the workspace in the biosafety cabinet }\end{array}$ & Recommendation based on experimental research [33] \\
\hline $\begin{array}{l}\text { Wash thoroughly cumulus-oocyte complexes to potentially dilute the } \\
\text { viral load }\end{array}$ & Recommendation based on expert opinion \\
\hline $\begin{array}{l}\text { Use protective eyewear and N95 masks when performing aerosol- } \\
\text { generating procedures }\end{array}$ & Recommendation based on expert opinion \\
\hline Semen ejaculate jars must be wiped prior to handling specimens & Recommendation based on expert opinion \\
\hline $\begin{array}{l}\text { Process sperm using a combination of sperm density gradient } \\
\text { techniques followed by a swim-up step }\end{array}$ & Recommendation based on expert opinion \\
\hline Collect the follicular fluid into well-sealed containers & $\begin{array}{l}\text { Recommendation based on committee opinion } \\
\text { guidelines (ESHRE COVID-19 taskforce) [18] }\end{array}$ \\
\hline $\begin{array}{l}\text { Use mechanical micropipettes and filtered tips. Following use, } \\
\text { disassemble and disinfect micropipettes using approved laboratory } \\
\text { agents and/or UV irradiation }\end{array}$ & Recommendation based on usual practice \\
\hline Use UV-sterilized liquid nitrogen & $\begin{array}{l}\text { Recommendation based on risk assessment } \\
\text { research [34] }\end{array}$ \\
\hline Use of closed system cryopreservation tools & $\begin{array}{l}\text { Recommendation based on committee opinion } \\
\text { guidelines (ESHRE COVID-19 taskforce) [18] }\end{array}$ \\
\hline Safeguard the integrity of the zona pellucida & Recommendation based on experimental research [35] \\
\hline
\end{tabular}

During a pandemic, manufacturing and distributing companies may lack the personnel to maintain a regular delivery schedule. This shortage would require the laboratory to increase preemptively its stock of PPE (gloves, surgical masks, and N95 masks) as well as culture and cryopreservation media batches while favoring products with longer expiration dates.

Along this perspective, supplies inventory should be updated regularly in order to match the workload. A reduction in the workload may also drive special considerations for resources management, such as the reduction of the number of operating incubators.

\section{Operational changes protecting embryologists and gametes/embryos}

It is reasonable to recommend that patients and staff be primarily triaged and regularly tested according to national recommendations and/or availability of laboratory testing. While ESHRE favored SARS-CoV-2 IgM/IgG immunologic screening, ASRM emphasized on viral 
molecular testing $[18,19]$. One should never underestimate the importance of personal hygiene and the use of proper PPE. Laboratory staff are expected follow standard laboratory practices, including wearing surgical masks, disposable gloves, and eye protection devices. It would be reasonable to add the use of a long-sleeve impermeable gown over the scrubs when performing an aerosol-generating procedure such as testicular tissue processing. In vitro experimental studies investigating the filtering capacity of standard surgical masks and N95 masks (FFP2) [28] showed that both types of masks retained at least $95 \%$ of small particles $(0.3 \mu \mathrm{m}$ corresponding to aerosols) offering comparable effective outward protection. Toward inward protection nonetheless was superior for N95 masks. It follows that while surgical masks may not be a perfect match to N95 masks, their usage is still encouraged. While the use of surgical masks is currently standard practice, N95 masks may be encouraged during aerosol-generating procedures. In view of the global shortage in facial masks during the COVID-19 pandemic, recommendations have been modified in order to take into account the local availability of PPE supply

It also follows that unnecessary patient visits to the IVF unit for the renewal of cryopreserved biological material should be reduced. Alternatively, payments and consents may be performed online. IVF staff should wear a surgical mask and practice social distancing at all times, more so when communicating information to patients. The role for telehealth is critical during pandemic time, and has been facilitated by the widespread use of Electronic medical record (EMR) systems for tasks including online billing, e-consents, and communications [36].

When discussing indoor laboratory air environment, no clear recommendations exist for the air purification system in IVF. Although high-efficiency particulate air (HEPA) filters are $99.97 \%$ efficient at collecting the most-penetrating particles $(\sim 0.3 \mu \mathrm{m})$, they may not adequately protect against smaller entities like viruses. But, since aerosolized viruses are thought to exist as agglomerates, the increase in the particle size may consequently cause them to be efficiently captured by the filter [37]. On the other hand, activated carbon filters normally installed within HVAC filter cartridges to trap volatile organic compounds, were found to absorb viral particles as well [38]. While most IVF laboratories are equipped with positive-pressure air systems, it may be recommended to switch to negative pressure modules during airborne virus outbreaks to sink the virus. This may be technically and financially challenging to many laboratories. In view of the restricted personnel number and laboratory space within the IVF working place, the risk benefit of discontinuing positive-pressure air purification must be properly assessed. The treatment of a patient who tested positive for COVID-19 for instance warrants the turning off of positive-pressure ventilation to avoid dissemination of the virus outside the operating theater. Particular consideration should also be given to increasing the number of air changes per hour and reducing recirculation of air in favor of using 100\% fresh air.

As for infection control prevention, embryologists are encouraged to follow standard practices in the IVF laboratory. Such practices include the cleaning of supply boxes and gas cylinders before entering the laboratory using approved disinfection agents [21]. In addition, the biosafety cabinet workspace should be routinely and thoroughly disinfected, with particular attention to the uncluttering of airflow outlets to avoid flow disruptive turbulence, which may increase the risk exposure of operators. Specifically, personnel should exercise laboratory housekeeping vigilance during high-risk pandemics. Cleaning practices must be diligently observed, such as disinfection of common surfaces (e.g., doorknobs, keyboards, surfaces...). Commercially available quaternaryammonium-based formulations, labeled "embryo-safe", were shown to be effective against coronaviruses [39]. More so, the combination of spraying and wiping with approved disinfectant, followed by UV irradiation for 30 min may completely inactivate the virus in biosafety cabinets [33].

Since coronaviruses were detected in the blood of infected patients [40] and in view of the presence of viral receptors on human spermatozoa, Sertoli cells, Leydig cells $[9,10]$, and oocytes [41], extra vigilance during handling biological material is highly justified. More specifically, standard precautions should be observed during routine handling of specimens, while special attention should be considered during aerosol-generating procedures such as processing of testicular tubules. The use of N95 masks, goggles or face shields may be more appropriate during sample preparatory steps that may generate aerosols or droplets and during mechanical processing of testicular tubules.

It should also be noted that universal precautions during oocyte pick up should be strictly taken, which include the collection of follicular fluid into well-sealed containers [18]. In addition, cumulus-oocyte complexes should be thoroughly and repeatedly washed with the aim of diluting viral load. While no recommendations are currently available for sperm processing during COVID-19 pandemics, precautions and procedures recommended for other viruses should be diligently followed. Semen ejaculate jars must be properly wiped prior to handling specimens. It is advisable to separate sperm using a combination of sperm density gradient techniques followed by a swim-up step to dilute the virus [42]. Sperm processing should include the frequent change of sterile pipettes and tubes prior to each 
washing step [43]. The use of mechanical micropipettes is recommended [26] and sterile-filtered tips pipettes are preferred to avoid aerosol generation and contamination of the micropipette. Following use, micropipettes must be disassembled and disinfected using approved laboratory agents and/or UV irradiation.

The safety of the cryopreservation process may be best observed when UV-sterilized liquid nitrogen is used [34] and when embryos and oocytes are sequentially washed. Special attention should be made to safeguarding the integrity of the zona pellucida which is considered an efficient barrier against viral contamination [35]. The use of closed system cryopreservation tools is preferred to secure the safety of the storage material [18]. Vapor tanks are also favored for cryostorage to minimize risks of viral transmission.

\section{Conclusion}

Planning for a crisis is one of the most important undertakings in a laboratory. Appropriate planning protects both personnel and gametes/embryos and ensures continuity of care. The planning process involves the prompt and proper identification of risks and the strict implementation of operational changes to address loss of staffing, shortage of supply, and changes in laboratory practices.

\section{Abbreviations}

ASRM: American Society for Reproductive Medicine; CAP: College of American Pathologists; CDC: Centers for Disease Control and Prevention; COVID-19: Coronavirus disease 2019; EMR: Electronic medical record; ESHRE: European Society for Human Reproduction and Embryology; FFP2: Filtering facepiece; HEPA: High-efficiency particulate air; IgG: Immunoglobulin G; IgM: Immunoglobulin M; IVF: In vitro fertilization; LN2: Liquid nitrogen; PPE: Personal protective equipment; SARS-CoV2: Severe acute respiratory syndrome coronavirus 2; SOP: Standard operating procedure; UV: Ultraviolet; WHO: World Health Organization

\section{Acknowledgements}

Not applicable.

\section{Authors' contributions}

FC wrote the manuscript. NY critically revised the article. FC, NY, and AH provided the current recommendations. All authors have read and approved the manuscript.

\section{Funding}

None.

\section{Availability of data and materials}

Not applicable

\section{Ethics approval and consent to participate}

Not applicable.

\section{Consent for publication}

Not applicable.

\section{Competing interests}

The authors declare that they have no competing interests.

\section{Author details}

Middle East Fertility Society Embryology Specialty Interest Group, Beirut, Lebanon. ${ }^{2}$ American University of Beirut Medical Center, Beirut, Lebanon. ${ }^{3}$ University of Jordan, Amman, Jordan. ${ }^{4}$ Quttainah Medical Center, Kuwait City, Kuwait.

Received: 8 May 2020 Accepted: 22 September 2020

Published online: 08 October 2020

\section{References}

1. of the International CSG (2020) The species severe acute respiratory syndrome-related coronavirus: classifying 2019-nCoV and naming it SARSCoV-2. Nat Microbiol 5:536

2. Otter J, Donskey C, Yezli S, Douthwaite S, Goldenberg S, Weber D (2016) Transmission of SARS and MERS coronaviruses and influenza virus in healthcare settings: the possible role of dry surface contamination. J Hosp Infect 92:235-250

3. World Health Organization aWho (2020) Coronavirus disease (COVID-2019) situation reports.

4. Prevention CfDCa. Coronavirus Disease 2019 (COVID-19) - how coronavirus spreads.

5. Day M (2020) Covid-19: identifying and isolating asymptomatic people helped eliminate virus in Italian village. BMJ 368

6. Koh D (2020) Occupational risks for COVID-19 infection. Occup Med 70:3

7. Assiri A, McGeer A, Perl TM, Price CS, Al Rabeeah AA, Cummings DA, Alabdullatif ZN, Assad M, Almulhim A, Makhdoom H (2013) Hospital outbreak of Middle East respiratory syndrome coronavirus. N Engl J Med 369:407-416

8. Guery B, Poissy J, El Mansouf L, Séjourné C, Ettahar N, Lemaire X, Vuotto F, Goffard A, Behillil S, Enouf V (2013) Clinical features and viral diagnosis of two cases of infection with Middle East respiratory syndrome coronavirus: a report of nosocomial transmission. Lancet 381:2265-2272

9. Fan C, Li K, Ding Y, Lu WL, Wang J (2020) ACE2 expression in kidney and testis may cause kidney and testis damage after 2019-nCoV infection MedRxiv

10. Colaco S, K Chhabria, N Singh, A Bhide, D Singh, A Singh, A Husein, A Mishra, R Sharma and N Ashary (2020) Expression of SARS-CoV-2 receptor ACE2 and the spike protein processing enzymes in developing human embryos. arXiv preprint arXiv:2004.04935.

11. Corona G, Baldi E, Isidori A, Paoli D, Pallotti F, De Santis L, Francavilla F, La Vignera S, Selice R, Caponecchia L (2020) SARS-CoV-2 infection, male fertility and sperm cryopreservation: a position statement of the Italian Society of Andrology and Sexual Medicine (SIAMS)(Società Italiana di Andrologia e Medicina della Sessualità). J Endocrinol Investig 1

12. Song C, Wang Y, Li W, Hu B, Chen G, Xia P, Wang W, Li C, Diao F, Hu Z (2020) Absence of 2019 novel coronavirus in semen and testes of COVID-19 patients. Biol Reprod

13. Pan F, Xiao X, Guo J, Song Y, Li H, Patel DP, Spivak AM, Joseph PA, Zhang X Xiong C (2020) No evidence of SARS-CoV-2 in semen of males recovering from COVID-19. Fertil Steril

14. Li D, Jin M, Bao P, Zhao W, Zhang S (2020) Clinical characteristics and results of semen tests among men with coronavirus disease 2019. JAMA Netw Open 3:e208292-e208292

15. Rademaker M (1994) Survival of virus in liquid nitrogen. N Z Med J 107:382382

16. Bielanski A, Vajta G (2009) Risk of contamination of germplasm during cryopreservation and cryobanking in IVF units. Hum Reprod 24:2457-2467

17. Morris GJ (2005) The origin, ultrastructure, and microbiology of the sediment accumulating in liquid nitrogen storage vessels. Cryobiology 50: $231-238$

18. group EC-W (2020) ESHRE guidance on recommencing ART treatments ESHRE website

19. (ASRM) ASFRM (2020) Patient management and clinical recommendations during the coronavirus (COVID-19) PANDEMIC

20. The Association of Reproductive and Clinical Scientists aTBFS (2020) Best practice guidelines for reintroduction of routine fertility treatments during the COVID-19 pandemic.

21. Society for Assisted Reproductive Technology (SART) tCoRBC, and the Society for Reproductive Biologists and Technologists (SRBT) (2020) Laboratory Guidance for Commencing or Continuing ART Operations During the Ongoing COVID-19 Pandemic. 
22. Kuhar DT, Carrico RM, Cox K, de Perio MA, Irwin KL, Lundstrom T, Overholt AD, Roberts KT, Russi M, Steed C (2019) Infection control in healthcare personnel: infrastructure and routine practices for occupational infection prevention and control services

23. Luangasanatip N, Hongsuwan M, Limmathurotsakul D, Lubell Y, AS Lee SH, Day NP, Graves N, Cooper BS (2015) Comparative efficacy of interventions to promote hand hygiene in hospital: systematic review and network metaanalysis. BMJ 351

24. Organization WH. Guiding principles for immunization activities during the COVID-19 pandemic.

25. Technology PCotSfAR and PCotASfR Medicine (2008) Guidelines for development of an emergency plan for in vitro fertilization programs. Fertil Steril 90:S131-S133

26. labs EGGoGPil (2016) Revised guidelines for good practice in IVF laboratories (2015). Hum Reprod 31:685-686

27. Tanks C (2020) Cryostorage of reproductive tissues in the in vitro fertilization laboratory: a committee opinion. https://www.reproductivefacts.org/ globalassets/asrm/asrm-content/news-and-publications/practice-guidelines/ for-non-members/cryostorage_of_reproductive_tissues.pdf.

28. van der Sande M, Teunis P, Sabel R (2008) Professional and home-made face masks reduce exposure to respiratory infections among the general population. PLoS One 3:e2618

29. Elder K, Van den Bergh M, Woodward B (2015) Troubleshooting and problem-solving in the IVF laboratory. Cambridge University Press

30. Schiewe M, Freeman M, Whitney J, VerMilyea M, Jones A, Aguirre M, Leisinger C, Adaniya G, Synder N, Chilton R (2019) Comprehensive assessment of cryogenic storage risk and quality management concerns: best practice guidelines for ART labs. J Assist Reprod Genet 36:5-14

31. Hellewell J, Abbott S, Gimma A, Bosse NI, Jarvis Cl, Russell TW, Munday JD, Kucharski AJ, Edmunds WJ, Sun F (2020) Feasibility of controlling COVID-19 outbreaks by isolation of cases and contacts. Lancet Glob Health

32. Chu DK, AkI EA, Duda S, Solo K, Yaacoub S, Schünemann HJ, El-harakeh A, Bognanni A, Lotfi T, Loeb M (2020) Physical distancing, face masks, and eye protection to prevent person-to-person transmission of SARS-CoV-2 and COVID-19: a systematic review and meta-analysis. Lancet.

33. Kariwa H, Fujii N, Takashima I (2006) Inactivation of SARS coronavirus by means of povidone-iodine, physical conditions and chemical reagents. Dermatology 212:119-123

34. Parmegiani L, Accorsi A, Cognigni GE, Bernardi S, Troilo E, Filicori M (2010) Sterilization of liquid nitrogen with ultraviolet irradiation for safe vitrification of human oocytes or embryos. Fertil Steril 94:1525-1528

35. Van Soom A, Wrathall A, Herrler A, Nauwynck H (2009) Is the zona pellucida an efficient barrier to viral infection? Reprod Fertil Dev 22:21-31

36. Hernández C, Valdera C, Cordero J, López E, Plaza J, Albi M (2020) Impact of telemedicine on assisted reproduction treatment in the public health system. J Healthc Qual Res 35:27-34

37. Helmbuch BK, JK Hodge and JD Wander (2007) Viral penetration of high efficiency particulate air (HEPA) filters. APPLIED RESEARCH ASSOCIATES INC TYNDALL AFB FL.

38. Reza MS, Hasan AK, Afroze S, Bakar MSA, Taweekun J, Azad AK (2020) Analysis on preparation, application, and recycling of activated carbon to aid in COVID-19 protection. Int J Integrated Eng 12:233-244

39. Li R, Yin T, Fang F, Li Q, Chen J, Wang Y, Hao Y, Wu G, Duan P, Wang Y (2020) Potential risks of SARS-Cov-2 infection on reproductive health. Reprod BioMed Online

40. Ng LF, Wong M, Koh S, Ooi E-E, Tang K-F, Leong H-N, Ling A-E, Agathe LV, Tan J, Liu ET (2004) Detection of severe acute respiratory syndrome coronavirus in blood of infected patients. J Clin Microbiol 42:347-350

41. SARS-CoV-2 host receptors ACE2 and CD147 (BSG) are present on human oocytes and blastocysts (2020) https://doi.org/10.1007/s10815-020-01952-x.

42. Fourie JM, Loskutoff $N$, Huyser C (2015) Semen decontamination for the elimination of seminal HIV-1. Reprod BioMed Online 30:296-302

43. Nicholson C, Abramsson L, Holm S, Bjurulf E (2000) Bacterial contamination and sperm recovery after semen preparation by density gradient centrifugation using silane-coated silica particles at different $\mathrm{g}$ forces. Hum Reprod 15:662-666

\section{Publisher's Note}

Springer Nature remains neutral with regard to jurisdictional claims in published maps and institutional affiliations.

\section{Submit your manuscript to a SpringerOpen ${ }^{\circ}$ journal and benefit from:}

- Convenient online submission

- Rigorous peer review

- Open access: articles freely available online

- High visibility within the field

- Retaining the copyright to your article

Submit your next manuscript at $\boldsymbol{\nabla}$ springeropen.com 